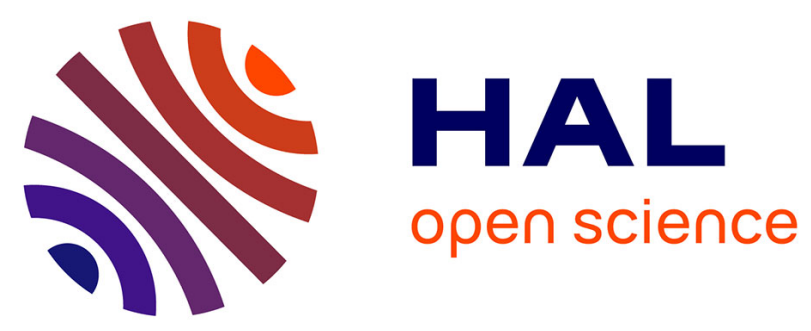

\title{
Optimised PLC power transfer on avionic DC Power Lines: Coupling circuit and lightning protection
}

Mickael Brison, Mohamed Bensetti, Raul de Lacerda, Filipe Vinci dos Santos, C Taurand

\section{To cite this version:}

Mickael Brison, Mohamed Bensetti, Raul de Lacerda, Filipe Vinci dos Santos, C Taurand. Optimised PLC power transfer on avionic DC Power Lines: Coupling circuit and lightning protection. 2017 IEEE International Symposium on Power Line Communications and its Applications (ISPLC), Apr 2017, Madrid, Spain. pp.1 - 6, 10.1109/ISPLC.2017.7897110 . hal-01577909

\section{HAL Id: hal-01577909 \\ https://hal.science/hal-01577909}

Submitted on 28 Aug 2017

HAL is a multi-disciplinary open access archive for the deposit and dissemination of scientific research documents, whether they are published or not. The documents may come from teaching and research institutions in France or abroad, or from public or private research centers.
L'archive ouverte pluridisciplinaire HAL, est destinée au dépôt et à la diffusion de documents scientifiques de niveau recherche, publiés ou non, émanant des établissements d'enseignement et de recherche français ou étrangers, des laboratoires publics ou privés. 


\title{
Optimised PLC power transfer on Avionic DC Power Lines: Coupling Circuit and Lightning Protection
}

\author{
M. Brison ${ }^{1,2,4}$, M. Bensetti ${ }^{1}$, R. De Lacerda ${ }^{3}$, F. Vinci Dos Santos $^{4}$, C. Taurand ${ }^{2}$ \\ ${ }^{1}$ GeePs - Group of electrical engineering - Paris, UMR CNRS 8507, CentraleSupélec, Univ Paris-Sud, Sorbonne \\ Universités, UPMC Univ Paris, 3-11 rue Joliot-Curie, Plateau de Moulon, 91192 Gif-sur-Yvette, France \\ ${ }^{2}$ Thales Avionics, Hardware department, 25 Rue Jules Védrines, 26000 Valence, France \\ ${ }^{3}$ L2S Laboratoire de Signaux et Systèmes - UMR CNRS 8506, CentraleSupélec/Université Paris-Sud, 3 Rue \\ Joliot-Curie, 91192 Gif-sur-Yvette, France \\ ${ }^{4}$ SANA - Advanced Analog Design Group, CentraleSupélec/Université Paris-Sud, 3 Rue Joliot-Curie, 91192 \\ Gif-sur-Yvette, France
}

\begin{abstract}
Power Line Communication (PLC) systems are good candidates for next-generation aircraft communication channels. On-board power buses must meet stringent safety requirements that mandate the use of Transient Voltage suppressors (TVS) for lightning protection. These devices strongly degrade the performance of the communication channel. In this paper we analyze the impact of the lightning protection circuit used in aircraft power buses both theoretically and experimentally. It is shown that TVS devices are responsible for distortion and attenuation in the PLC signal band ( $1 \mathrm{MHz}-100 \mathrm{MHz})$. We introduce a novel co-design strategy, matching PLC coupler to lightning protection conforming to air travel safety regulations. Our experimental results demonstrate that both constraints can be met using our proposed architecture.
\end{abstract}

Keywords-Broadband PLC, Avionics, Transient Voltage Suppressor, Co-design, Lightning protection, Modeling.

\section{INTRODUCTION}

Mass reduction is a constant preoccupation in the aeronautic industry but newer in-flight entertainment, control and monitoring systems introduce more and more cables all over the aircraft. Several joint industrial-academic efforts have been undertaken to reduce the number of cables required for proper functioning of all the aircraft's systems [1]. For example, Power over Data with the AFDX bus and Power Line Communication (PLC) are envisaged solutions.

Early studies targeted non-critical data channels and non real time applications. In this paper we focus on the use of PLC technology developed for Home Area Networks (HANs) over low voltage domestic power lines, so called Broad-Band (BB) PLC. Despite the fact that BB PLC has been considered for aeronautic and aerospace applications since several years [2], [3], there is still no accepted solution.

Targeted goals are :

- Weight savings;

- Easy and cost-effective installation and possibly retrofit;

- Cost-effective and smart maintenance.

PLC consists in using the electrical energy distribution network to transport both power and data [4]. The PLC concept has led to the deployment of both very high speed data networks over short distances, as well as low speed networks spanning hundreds of kilometers. Each kind of PLC system serves different needs and markets [5]. BB PLC seems to be the most readily adaptable to aircraft [6] given that the latest BB PLC equipment for home use reaches throughput as high as 1 Gigabits/s (Gbps) [7]. Moreover, recent research endeavors yielded encouraging results with regard to integration of $\mathrm{BB}$ PLC in the avionic environment [8]. On-board PLC systems must deal with several issues to ensure high data transfer rates over wire not specifically deployed for communication purposes:

- Frequency-dependent impairments:

- Attenuation due to the presence of lightning protection devices [9] ;

- Unusable frequencies bands due to multiple paths and impedance mismatches [10] ;

- Gaussian colored noise generated by other equipments [11] ;

- Tight constraints on electromagnetic emissions due to the EMC regulations for aircraft:

- Conducted and radiated [12], [13] ;

- Strong coupling between cables [14].

Apart from noise, impedance mismatch is the key limiting factor for the communication channel. The main source of BB PLC impedance mismatch is the input filter that must be added to all avionics equipments drawing power from the wire. This input filter contains lightning protection devices and electromagnetic compatibility (EMC) filters, both affect input impedance. This article will focus on lightning protection devices, for this purpose we suppose that the EMC filter will not affect the input impedance which will only be affected by the lightning protection devices.

The impact of common surge protection devices on the PLC signal has been investigated in the context of Narrowband PLC (NB PLC) often used in smartgrids applications [15]. It is shown that the varistors, located at the input of connected equipment, impair the signal transmission quality [9], [16]. 
In a similar vein, our study deals with the effect of lightning protection devices currently used in avionics.

This paper is organized as follows. Section II describes briefly the power network of an aircraft and the lightning protection problem. Section III discusses the modeling of a specific lightning protection device, the Transient Voltage Supressor (TSV). Section IV details a possible deployment scenario for a BB PLC channel using the low voltage power network of the aircraft containing TSVs, and discusses their impact on the channel transfer function. Finally, section V proposes a co-design approach of the input filter for an equipment with the PLC coupling circuit to ensure an optimal signal power transfer between two PLC modems. Measurements corroborate the theoretical analysis and simulation results.

\section{Aeronautic Power Network And lightning PROTECTION}

In legacy aircrafts, usually two types of electrical power networks are deployed throughout the body of the plane, a three-phase alternating current (AC) network $115 \mathrm{~V} / 400 \mathrm{~Hz}$ and a $28 \mathrm{~V}$ direct current (DC) network. Here we will focus on $28 \mathrm{~V}$ DC power lines. The main power distribution unit is connected to a busbar. Multiples wires from this busbar are connected to Solid State Power Controllers (SSPC). The SSPC regulates the voltage and/or current supplied to each load. The SSPC is connected to a load (for 28V DC network) by a wire (Gauge 20 copper wire), and the return current goes through the fuselage of the plane. Hence, the fuselage is the electrical ground and/or the return current path for all electrical equipment aboard. The specific case of a lightning strike hitting the plane is an important occurrence to consider for the aircraft systems designers.

Indeed, a civilian aircraft is hit by lightning every 1000 flight hours [17], on average. Every strike induces a current in the fuselage as well as currents on cables running inside the aircraft. These currents can damage the equipments connected to these lines. Protecting these systems against these events is essential for the well being of the aircraft and for all the people aboard. The induced currents have been modeled, and appear in the aeronautic standard DO-160 section 22 [12] as typical test waveforms to be used during the pin injection tests. To counter the effects of these surges, by diverting the energy away from equipment and people, one can use different surge protection devices.

Common surge protection devices used in the industry are :

- Metal Oxyde Varistors (MOV);

- Gas Discharge Tube (GDT);

- Transient Voltage Suppressor (TVS).

The avionics designers use mainly the TVS for surge protection. MOVs are avoided because their behavior changes with aging [18], while the GDT exploits electric arcing phenomena that can't be easily controlled on DC power lines . Unfortunately, TVSs disturbs the PLC signal due to the parasitic elements in these devices. For example, the effect of the clipping of the TVS on the NB PLC signal has been noted in [19]. Our concern here are BB PLC signals that use far higher frequency bands than those studied in [19].

\section{TVS MODELING}

TVS protect circuits from voltage spikes (transients) that appear due to induced current surges or by Electro Static Discharge (ESD) phenomena. When a transient overvoltage occurs, the TVS conducts current near instantly, hence limiting the voltage to a safe level called clamping voltage (Vc). The potentially damaging current flows through the TVS instead of the protected circuit [20], see Fig. 1.
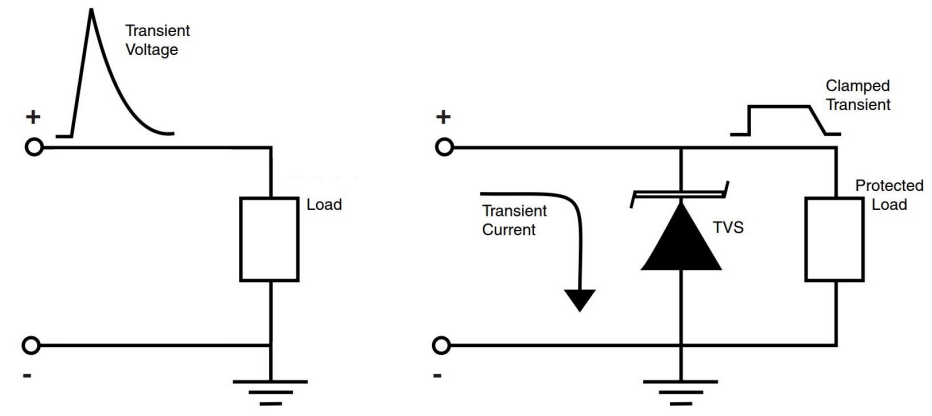

Fig. 1. TVS : Surge protection principle [20]

The TVS is modeled as a RLC series circuit [21]. This model is valid for high frequency, small signal excitation, hence the same conditions of interest for BB PLC. The values of $\mathrm{R}, \mathrm{L}$ and $\mathrm{C}$ can be determined from impedance ( $\mathrm{Z}$ ) measurements on a vector network analyzer where :

- $R=Z$ at the resonance frequency;

- $C=\frac{1}{2 \pi f Z(f)}$ at $\mathrm{f}=1 \mathrm{MHz}$;

- $L=\frac{1}{4 \pi^{2} f_{r}^{2} C}$ with $f_{r}$ as the resonance frequency.

The TVS is otherwise "invisible" until a transient appears, meaning that breakdown voltage, standby current and parasitic capacitance have no effect on normal circuit performance.

To check the model above, we measured the impedance of a TVS (SMCJ26CA [22]) and compared it to the Vishay model (Fig. 2). Measurements were done on the VNA Keysight $\mathrm{E} 5071 \mathrm{C}$, in the frequency range $100 \mathrm{kHz}$ to $500 \mathrm{MHz}$. The measurements resulted in the following values :

- $R=0.047 \Omega, C=1.034 n F, L=3.025 n H$;

These parameters were extracted using the genetic algorithm adopted in [23].

One can observe that between $1 \mathrm{MHz}$ and $100 \mathrm{MHz}$ the capacitive behavior predominates. This would lead to significant losses in the signal power transfer function between two PLC modems linked by a wire protected by this TVS.

\section{USE OF BB PLC OVER AIRCRAFT EQUIPMENT WITH LIGHTNING PROTECTION}

In the case of a simple transmission line, it is commonly known that to avoid reflections one must have $Z_{\text {modem }}=Z_{c}$ where $Z_{c}$ is the characteristic impedance of the line and $Z_{\text {modem }}$ the impedance of the PLC modem. In commercial 


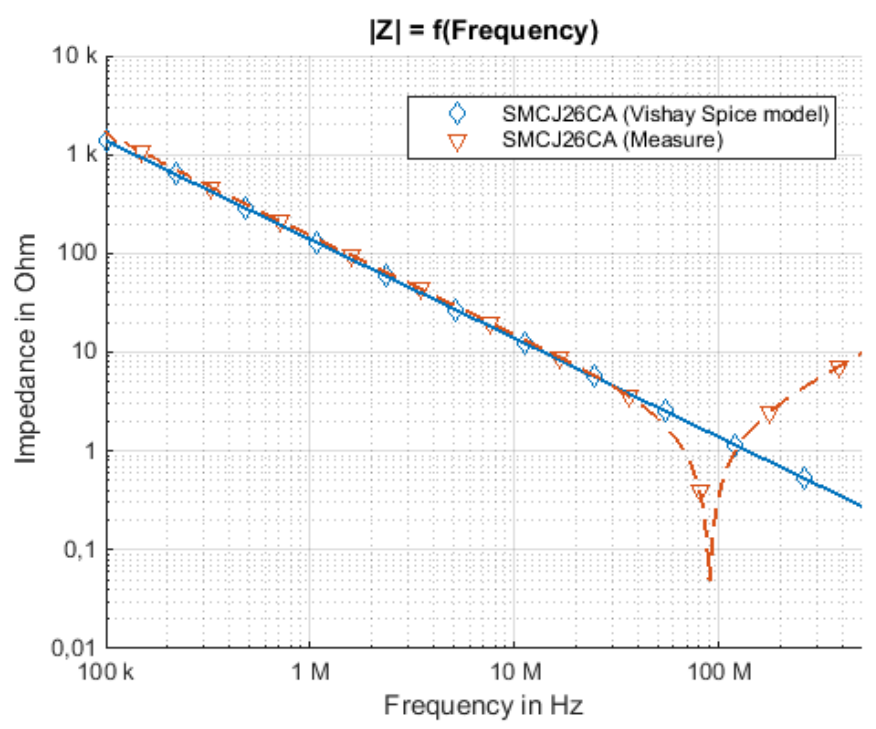

Fig. 2. Impedance of the TVS SMCJ26CA [22]

BB PLC couplers, this is achieved by putting inductors L1 and L2 right after the coupling of the PLC signal, as shown in Fig. 3. The capacitances in the schematics are used to filter the low frequency power signal. $Z_{\text {equipment }}$ correspond to the impedance of the equipment connected to the residential plug. In this circuit the capacitive part of the lightning protection devices (dotted part on Fig. 3) that would affect the transfer function is then compensated by the high impedance of the inductance in the frequency range of interest, hence the signal transfer function is not degraded.

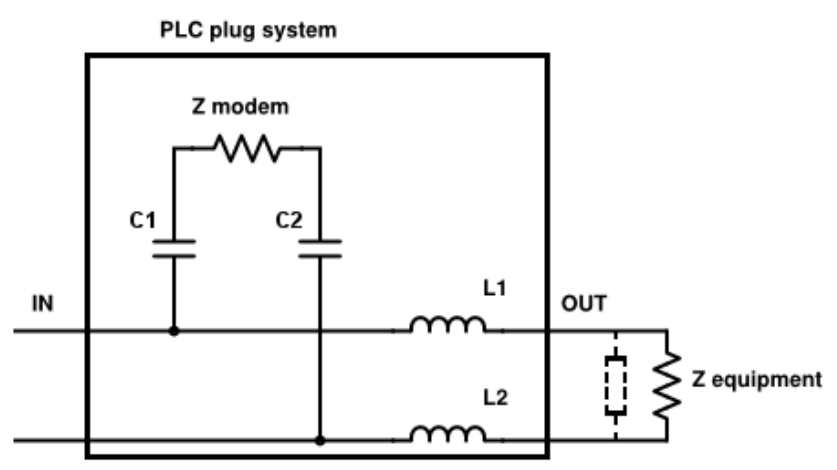

Fig. 3. Common bifilar BB PLC configuration

In the frequency range $1 \mathrm{MHz}$ to $100 \mathrm{MHz}$, we have :

$$
\begin{array}{r}
Z_{\text {in }}=\left(Z_{\text {modem }}+Z_{C 1}+Z_{C 2}\right) / / \\
\left(Z_{\text {equipment }}+Z_{L 1}+Z_{L 2}\right) \approx Z_{\text {modem }}
\end{array}
$$

This type of coupling circuit cannot be applied in an aircraft because of lightning protection regulations. Indeed, a pin injection test must be done to validate this equipment [12].
During the pin injection tests, the current will go through the two inductors and the lightning protection device.

Such tests lead to very high currents in the coupling circuit that would damage the filter inductors. This means the lightning protection devices must be inserted before the inductors L1 and L2, at the same level of the PLC signal coupling like shown on the Fig. 3. The insertion of the lightning protection, in our case is a TVS, would lead to the Fig. 4. The presence of the TVS degrades considerably the transfer function between the two PLC modems.

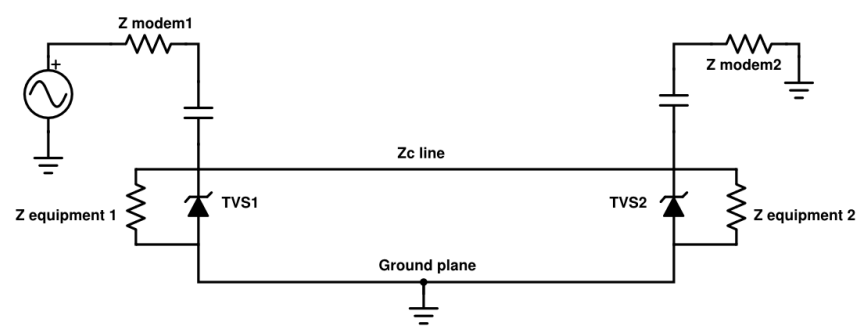

Fig. 4. Transmission line configuration

Indeed, in the simplest transmission line set-up, shown on Fig. 4, we have :

$$
Z_{\text {in }}=\left(Z_{\text {modem }}+Z_{\text {Cap }}\right) / / Z_{T V S} / / Z_{\text {equipment }}
$$

For the following calculation, let's assume that $Z_{\text {equipement }}=$ $\infty$ due to the EMC filter and $Z_{T V S}<<Z_{\text {modem }}$. Therefore :

$$
Z_{\text {in }} \approx Z_{T V S}
$$

This leads to impedance mismatch in the transmission line and the majority of the signal current is going into the TVS instead of the modem. Fig. 5 shows the simulated transfer function from equipment 1 to equipment 2 in the case of $Z_{\text {modem }} \approx Z_{c}$ with the TVS present (dashed line). The cable model used for the transmission line is a FCV06 [24], located $5 \mathrm{~cm}$ above a copper ground plane. It is clear that the TVS impacts negatively the transfer function.

A common solution for this problem in the case of BB PLC in the realm of HANs, is to replace the protection device ( MOV or TVS ) by GDTs due to the extremely low capacitance of these devices [25]. As mentioned before, using GDTs is awkward on aircraft DC power networks, precluding us from adopting it. The solution we propose is a concurrent design method for both the coupling circuit part and the input filter of the equipment. This is a viable proposal for aircraft equipment since every one of them is designed, built and tested to stringent specifications, hence building a PLC coupler matched to the equipment and the cable does not add much, cost-wise.

\section{EQUIPMENT INPUT FILTER AND PLC COUPLING CIRCUIT CO-DESIGN}

The main idea is to propose a concurrent design of the PLC coupling circuit with the input filter to obtain in the optimum case $Z_{\text {in }}=Z_{\text {modem }}=Z_{c}$, see Fig. 6. The component were selected using analytic formulas for the matching and protection level requirements. 


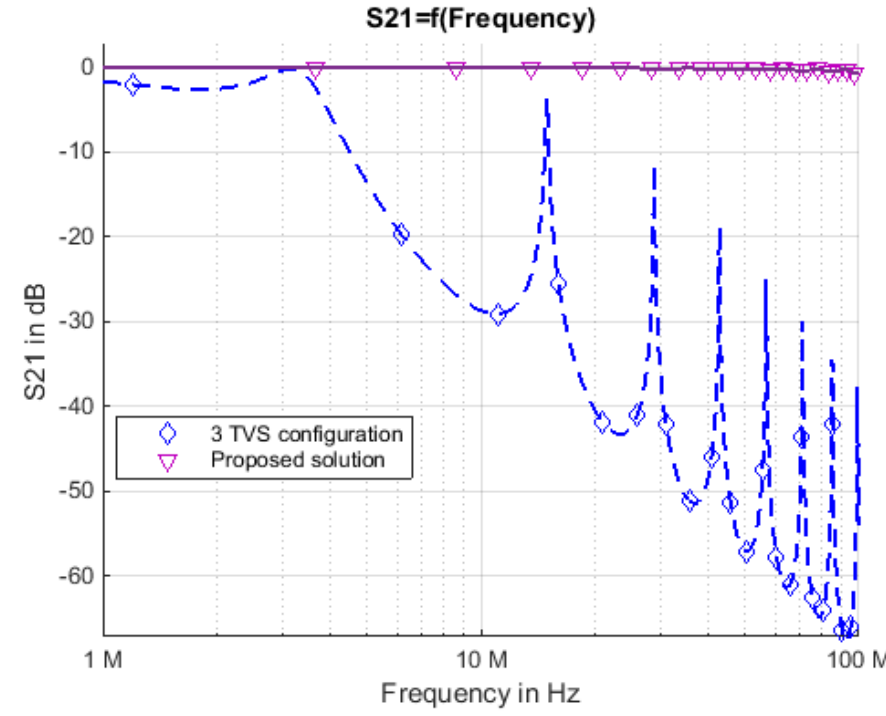

Fig. 5. Simulated transfer function from 1 to 2 with the TVS with the proposed solution on a 10 meters line

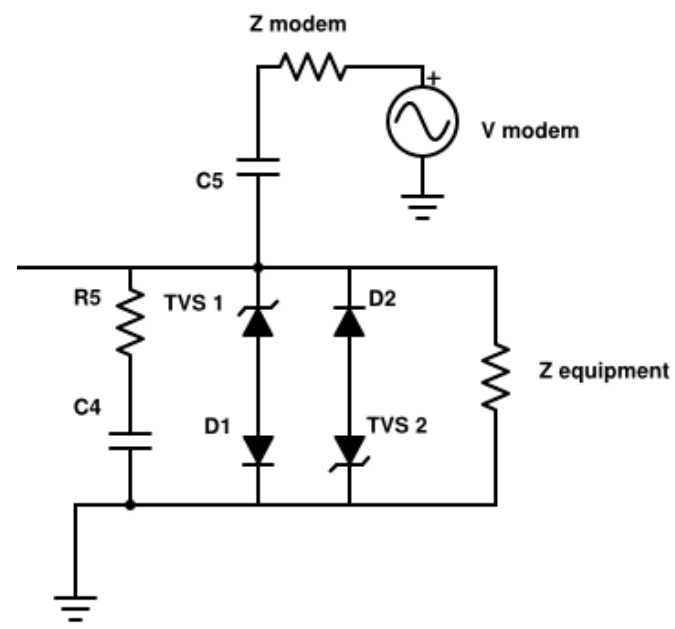

Fig. 6. Simplified schematic of the proposed solution

In this circuit, the choice of the diode is crucial and three parameters have to be considered:

- The diode must have a low parasitic capacitance to permit:

$$
Z_{T V S+D}=Z_{T V S}+Z_{D} \approx Z_{D}
$$

with the $D$ parasitic capacitance chosen as:

$$
Z_{\text {modem }} / / Z_{T V S+D} \approx Z_{\text {modem }}
$$

- The maximum peak current of the diode $I_{p p}$, must be greater than the TVS peak current rating otherwise the diode will fail before the protection.

- The breakdown voltage of the diode has to be greater than the clamping voltage of the TVS.
The RC series circuit compensates the resonance that is created by the line and the parasitic capacitance of the TVS+Diode part. We have :

$$
Z_{R}+Z_{C} \approx Z_{R} \text { with } Z_{R} / / Z_{\text {modem }} \approx Z_{\text {modem }}
$$

Assuming that $Z_{\text {equipement }}=\infty$ we have :

$$
\begin{aligned}
Z_{\text {in }}=\left(Z_{\text {modem }}+Z_{C 5}\right) / /\left(Z_{R}+Z_{C}\right) / / \\
\left(Z_{D}+Z_{T V S}\right) / /\left(Z_{D}+Z_{T V S}\right) \approx Z_{\text {modem }}
\end{aligned}
$$

In the case of an equipment wired to the $28 \mathrm{VDC}$, our lightning protection is composed of three TVS (SMCJ26CA) in series (e.g. TVS1 in Fig. 6), hence we chose three S07D diodes [26](e.g. D1 in Fig. 6) to modify the lightning protection. Fig. 7 shows the measured input impedance of the simulated cases depicted on Fig. 5. The continuous line in Fig. 5 shows the transfer function of the simple set-up discussed in section IV, with this circuit. We can see that, by using the proposed solution, the influence of the lightning protection, composed by the TVSs and the diodes, is negligible.

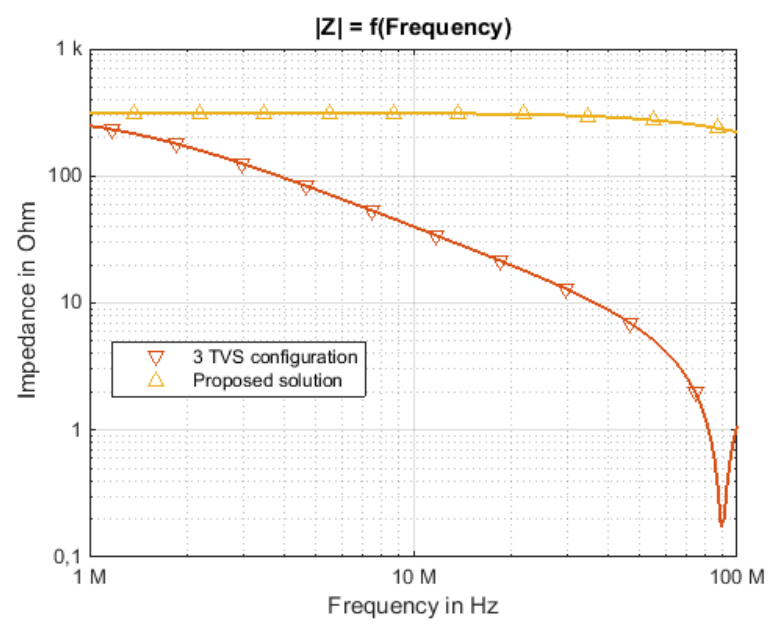

Fig. 7. Measured input impedance of the system with the TVS lightning protection only and with our proposed solution

For experimental validation, a setup similar to the model shown in Fig.4 was built. Three configurations were tested :

- Without any protection;

- With a protection composed of three TVS SMCJ26CA (in series);

- With the proposed protection composed of 3 TVS SMCJ26CA and 3 diodes S07D diodes (in series).

The VNA ports 1 and 2 were calibrated to $Z_{0}=330 \Omega$ to electrically replace the two modems. The transmission line was composed of a ten meters FCV06 wire located five centimeters above a ground plane (Fig.8). Fig.9 shows the measured transfer function in each configuration.

The measured results in Fig.9 match well the simulations shown in Fig.5. In the frequency range 1-100 MHz, the TVS deteriorate the transfer function, as predicted. The proposed 


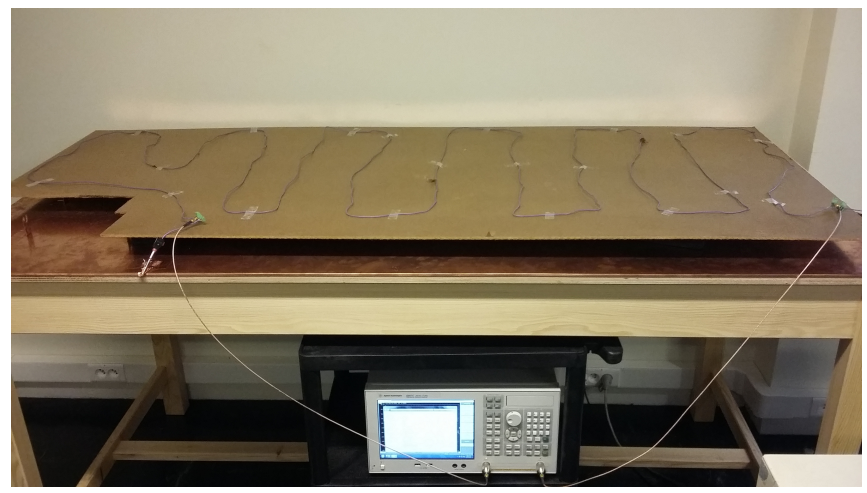

Fig. 8. Experimental test setup

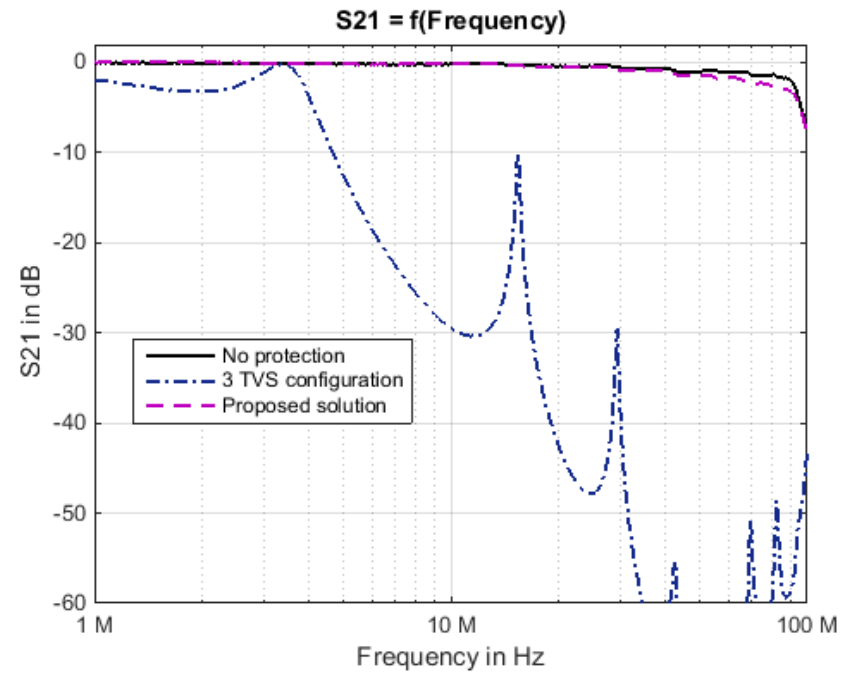

Fig. 9. Measured transfer function from 1 to 2 without protection, with three TVS, and with the proposed solution

solution permits to meet both the lightning protection requirements and simultaneously maintain a reasonably good transfer function between the endpoints.

This experiment demonstrates that BB PLC communication channels for aircraft DC power networks can be established despite the presence of the TVS by adopting a co-design methodology of the input filter and the PLC coupler, hence guaranteeing optimal signal power transfer between two PLC modems. The choice of the component will be dependent of the lightning protection level required by the system and so will be customized to each specific equipment.

\section{CONCLUSION AND PERSPECTIVES}

This paper discussed the effects of a lightning protection device (TVS) compatible with aircraft requirements on the transfer function between two PLC modems. The parasitic capacitance of the TVS hinders considerably the BB PLC signal by degrading the signal transfer function at higher frequency bands. Our solution consists on the use of a coupling circuit matched to the electrical properties of the devices and the line. The laboratory measurements show that the codesigned solution proposed in this paper is an effective answer for this problem. Future developments will focus on the codesign of the lightning protection circuitry together with the EMC filter in order to obtain an optimized coupler for the aircraft 28V DC power bus. Further work will aim to establish the impact of the complete optimized coupling circuit on the actual data transfer speeds of industrial G.hn modems under consideration for civilian aircraft PLC systems.

\section{REFERENCES}

[1] Transmission in Aircraft on Unique Path wirEs : Publishable Summary, 2012. [Online]. Available: http://www.transport-research.info/sites/default/files/project/ documents/8596/final1-taupe-0-lab-m42-publishable-report-0-5.pdf

[2] P. Chopra, S. Dangeti, and Z. Liu, "Interfacing power line communications to airborne vehicles: A technical review." Warrendale, Penn., 2008.

[3] M. D'Amore, K. Gigliotti, M. Ricci, and M. Sarto, "Feasibility of broadband power line communication aboard an aircraft," in Electromagnetic Compatibility - EMC Europe, 2008 International Symposium on, Sept 2008, pp. 1-6.

[4] A. Schwager, "Powerline communications: significant technologies to become ready for integration," Ph.D. dissertation, 2010. [Online]. Available: http://duepublico.uni-duisburg-essen.de/servlets/ DerivateServlet/Derivate-24381/Schwager_Andreas_Diss.pdf

[5] L. T. Berger, P. Pagani, A. Schwager, and P. Janse van Rensburg, "Introduction to power line communication channel and noise characterisation," in MIMO power line communications : narrow and broadband standards, EMC, and advanced processing, ser. Devices, Circuits, and Systems. CRC Press, 2014, pp. 3 - 37. [Online]. Available: https://hal.archives-ouvertes.fr/hal-01007573

[6] V. Degardin, E. Simon, M. Morelle, M. Lienard, P. Degauque, I. Junqua, and S. Bertuol, "On the possibility of using plc in aircraft," in Power Line Communications and Its Applications (ISPLC), 2010 IEEE International Symposium on, March 2010, pp. 337-340.

[7] L. T. Berger, A. Schwager, S. Galli, P. Pagani, D. M. Schneider, and H. Lioe, "Current Power Line Communication Systems: A Survey," in MIMO power line communications : narrow and broadband standards, EMC, and advanced processing, ser. Devices, Circuits, and Systems. CRC Press, 2014, pp. 253 - 269. [Online]. Available: https://hal.archives-ouvertes.fr/hal-01066411

[8] K. Kilani, V. Degardin, P. Laly, M. Lienard, and P. Degauque, "Impulsive noise generated by a pulse width modulation inverter: Modeling and impact on powerline communication," in 2013 IEEE 17th International Symposium on Power Line Communications and Its Applications, March 2013, pp. 75-79.

[9] S. Kim and T. Jeon, "Effects of surge protection devices on performances of plc systems," International Journal of Control and Automation, vol. 6, no. 3, pp. 239-248, 2013.

[10] M. Zimmermann and K. Dostert, "A multipath model for the powerline channel," Communications, IEEE Transactions on, vol. 50, no. 4, pp. 553-559, Apr 2002.

[11] D. Umehara, T. Hayasaki, S. Denno, and M. Morikura, "The influence of time-varying channels synchronized with commercial power supply on plc equipments," in Power Line Communications and Its Applications, 2008. ISPLC 2008. IEEE International Symposium on, April 2008, pp. 30-35.

[12] Environmental conditions and Test procedures for airborne equipment, DO-160, RTCA DO-160, 2010. 
[13] S. Dominiak, G. Vos, T. ter Meer, and H. Widmer, "Achieving emc emissions compliance for an aeronautics power line communications system," in Aerospace EMC, 2012 Proceedings ESA Workshop on, May 2012, pp. 1-6.

[14] S. Dominiak, H. Widmer, M. Bittner, and U. Dersch, "A bifilar approach to power and data transmission over common wires in aircraft," in Digital Avionics Systems Conference (DASC), 2011 IEEE/AIAA 30th, Oct 2011, pp. 7B4-1-7B4-13.

[15] K. Dostert, M. Sigle, and W. LIU, "Narrowband characterisation in an office environmnt," in MIMO power line communications : narrow and broadband standards, EMC, and advanced processing, ser. Devices, Circuits, and Systems. CRC Press, 2014, pp. 39 - 67.

[16] T. O. Sanya, M. Hove, A. J. Snyders, and H. C. Ferreira, "Surge protection of communication equipments for power line communication: Effects on communication signal," in AFRICON, 2011, Sept 2011, pp $1-4$.

[17] A. Jazzar, "Modélisation électromagnétique d'un choc de foudre en aéronautique," Ph.D. dissertation, 2012, thèse de doctorat dirigée par Clavel, Edith et Meunier, Gérard Sciences et technologie industrielles Grenoble 2012. [Online]. Available: http://www.theses.fr/ 2012GRENT077

[18] C. de Salles, M. L. B. Martinez, and . A. A. de Queiroz, "Ageing of metal oxide varistors due to surges," in Lightning Protection (XI SIPDA), 2011 International Symposium on, Oct 2011, pp. 171-176.

[19] M. Hove, T. O. Sanya, A. J. Snyders, I. R. Jandrell, and H. C. Ferreira, "The effect of type of transient voltage suppressor on the signal response of a coupling circuit for power line communications," in AFRICON, 2011, Sept 2011, pp. 1-6.

[20] B. Hartwig, "What is a Silicon Transient Voltage Suppressor and how does it work?" Vishay Semiconductors, Mar, vol. 1, p. 2, 2004.

[21] J. Lepkowski and W. Lepkowski, "Evaluating TVS protection circuits with SPICE," Power Electronics Technology, vol. 32, no. 1, p. 44, 2006.

[22] Datasheet SMCJ5.0A thru SMCJ188CA, Vishay General Semiconductor, 12 2013, rev. 10-Dec-13. [Online]. Available: http://www.mouser.com/ds/2/427/smcj50a-241829.pdf

[23] J. Taki, M. Bensetti, and D. Sadarnac, "Reduction of electromagnetic perturbations by optimizing the printed circuit board," in ISEF 2015, Valencia, Spain, Sep. 2015. [Online]. Available: https: //hal-centralesupelec.archives-ouvertes.fr/hal-01215835

[24] Datasheet FCSV-FCV, PLASTHERM, 05 2014. [Online]. Available: http://www.plastelec.com/en/document-2065.html

[25] H. Iwao, H. Kijima, and K. Takato, "An influence on transmission characteristics of power line communication when using surge protective devices," in Power Line Communications and Its Applications, 2008. ISPLC 2008. IEEE International Symposium on, April 2008, pp. 218 221.

[26] Datasheet S07B, S07D, S07G, S07J, S07M, Vishay General Semiconductor, 3 2015, rev. 18-Mar-15. [Online]. Available: http://www.vishay.com/docs/85733/s07b.pdf 